\title{
Eksplorasi Corporate Social Responsibility (CSR) Aplikasinya pada Industri Pariwisata di Ubud, Bali
}

\author{
Ida Ayu Putri Widawati
}

Magister Terapan Pariwisata, Politeknik Pariwisata Bali

Jl. Darmawangsa, Nusa Dua, Kampial, Kabupaten Badung, Bali

putri7widawati@gmail.com

Received: Mei, 2021

Accepted: Mei, 2021

Published: June, 2021

\begin{abstract}
This study explores how to apply Corporate Social Responsibility (CSR) to the tourism industry, especially the Travel agencys in Ubud Gianyar. Is it in line with the concept of environmentally friendly travel? The implementation of CSR can be done by building stages, such as an understanding of mature in the implementation of CSR where based on understanding and practice CSR is carried out in accordance with 5 stages in organizational learning, namely the defensive, compliance, managerial, and strategic stages. This study used a qualitative approach. Data were collected through in-depth interviews with the company. From the seventeen existing travel agencies, eight travel agencies were interviewed. Most of the Travel agencys in Ubud are still at the reactive level, namely responding by providing support for stakeholder activities, although some of them have been proactive and active. The practice of CSR is only in the defensive and compliance stages, namely the building stage, such as building an image in the community. Only a few are already at the managerial and strategic level.
\end{abstract}

Keywords: travel agencys, CSR, organizational learning

\begin{abstract}
Abstrak
Penelitian ini mengeksplorasi bagaimana aplikasi Corporate Social Responsibility (CSR) pada industri pariwisata khususnya Biro Perjalanan Wisata yang ada di Ubud Gianyar. apakah sejalan dengan konsep environmentally friendly travel. Penerapan CSR dapat dilakukan dengan membangun tahapan, seperti halnya pemahaman atas mature (kematangan) dalam penerapan CSR dimana berdasar pemahaman dan praktek CSR dilaksanakan sesuai dengan 5 tahap dalam organizational learning yakni tahap defensive, compliance, managerial, dan strategic. Penelitian ini menggunakan pendekatan kualitatif Data dikumpulkan melalui wawancara mendalam), dengan pihak perusahaan, dari tujuh belas Biro Perjalanan Wisata yang ada, berhasil diwawancarai delapan Biro Perjalanan Wisata. Sebagian besar Biro Perjalanan Wisata di Ubud masih dalam tataran reaktif yakni memberi respon dengan memberi dukungan atas kegiatan pemangku kepentingan, walaupun ada diantaranya sudah melakukan secara proaktif dan aktif. Praktek CSR baru pada tahap defensive dan compliance yakni tahap membangun yakni membangun image di masyarakat. Hanya beberapa yang sudah pada level managerial dan strategic.
\end{abstract}

Kata kunci: biro perjalanan wisata, CSR, organizational learning 


\section{PENDAHULUAN}

Pariwisata membawa dampak positif dan negatif terhadap lingkungan, ekonomi dan sosial. Yang terpenting adalah bagaimana mengeliminir dampak negatif dengan tetap mempertahankan dampak positif pariwisata yakni memaksimalkan manfaat (Charter, 1994). Dampak positif pariwisata dapat kita lihat dari terciptanya peluang kerja di masyarakat, peningkatan aktifitas ekonomi, peningkatan valuta asing, perlindungan terhadap lingkungan, meningkatnya infrastruktur dan kemakmuran masyarakat (Archer Coover, \& Ruhanen 1998; Buckley \& Pannell, 1990). Dampak negatif pariwisata dapat berupa degradasi lingkungan, perpindahan penduduk asli, kebocoran ekonomi, meningkatnya biaya hidup, terkikisnya budaya dan meningkatnya angka kriminal (Lepp, 2007; Mathieson \& Wall, 1982).

Isu berkembangnya masalah pencemaran lingkungan secara global, berkurangnya sumber daya, dan terjadinya pemborosan energi telah menarik banyak perhatian industri pariwisata, hal ini disebabkan karena besarnya tekanan terhadap perusahaan dari pihak media, karyawan, pemasok, aktivis kelompok sosial, pemerintah, dan pemangku kepentingan terkait lainnya. Hal ini mendorong perusahaan untuk ikut berperan memikul tanggung jawab sosial (corporate social responsibility) secara lebih serius. Ada keyakinan yang berkembang bahwa perusahaan seharusnya tidak hanya peduli tentang bagaimana meraih keuntungan yang optimal tetapi juga bagaimana agar bisa berkontribusi terhadap masyarakat luas.

Konsep Corporate Social Responsibility (CSR) bertujuan untuk mengintegrasikan masalah lingkungan dan sosial ke dalam operasi bisnis sehari-hari secara sukarela (Steurer, 2010). Praktek CSR telah diadopsi oleh sejumlah perusahaan besar di sebagian besar negara (Welford, 2004). Banyak pebisnis memahami bahwa kesediaan untuk memikul tanggung jawab bagi masyarakat dan lingkungan dapat menentukan pencapaian profitabilitas perusahaan (Collier \& Estebban, 2007). Pelanggan dan masyarakat cenderung memiliki sikap yang menguntungkan terhadap perusahaan yang lebih bertanggung jawab secara sosial.

Corporate Social Responsibility (CSR) adalah fenomena bisnis yang telah mendapat perhatian dari organisasi perusahaan baik itu dalam skala besar maupun kecil di seluruh Dunia (Kang, Lee, \& Huh, 2010; Turcsanyi \& Sisaye, 2013; Waldman, Kenett, \& Zilberg, 2010). Secara umum CSR mengandung pengertian bahwa suatu organisasi atau perusahaan memiliki suatu tanggung jawab terhadap konsumen, karyawan, pemegang saham, komunitas dan lingkungan dalam segala aspek operasional perusahaan (Crowther \& Aras, 2008; Hadi, 2011). Hal ini sejalan dengan pendapat John Elkington yang mengemukakan Triple Bottom Line Theory bahwa perusahaan bukan hanya bertujuan untuk menghasilkan keuntungan semata (economic) tetapi juga hendaknya memperhatikan aspek masyarakat (social) dan lingkungan sekitarnya (environmental) (Rahmatullah, 2010; Yogimitha, 2011). Penulis lain mengemukakan the triple bottom line concept menyangkut people, profit dan planet, sebenarnya memiliki arti yang sama dengan aspek social, economic dan environmental (Mattera \& Melgarejo, 2012)

Penerapan CSR dalam industri pariwisata tergolong relatif baru dibandingkan dengan perusahaan-perusahaan lainnya dalam lingkup global. Konsep sustainable tourism merupakan hal vital, bagaimana menjalankan bisnis bidang pariwisata untuk mengadopsi CSR melalui pendekatan pariwisata untuk mengeliminir pengaruh negatif dengan mengimplementasikan konsep sustainable melalui bentuk ecotourism, alternative tourism, green tourism, dan environmentally friendly travel. (Nyahunzvi, 2013). Tanpa adanya komitmen untuk tetap berkelanjutan maka sumber daya yang sangat menarik bagi wisatawan di suatu tempat, tapi justru industri di tempat tersebut tidak dapat berkembang. Dengan alasan tersebut pariwisata dan hospitaliti mulai memiliki inisiatif dalam menerapkan CSR. 
Hasil penelitian Kotler dan Lee (2005) dan Yu, Day, Adler dan Cai (2012) menyatakan bahwa perusahaan yang telah melaksanakan tanggung jawab sosialnya (dalam hal ini CSR) dapat meningkatkan penjualan dan pangsa pasar, menguatkan brand positioning, meningkatkan citra perusahaan, meningkatkan kemampuan untuk menarik, memotivasi dan mempertahankan karyawan, menurunkan biaya operasional dan meningkatkan daya tarik perusahaan terhadap investor dan analis keuangan.

Pemerintah Indonesia bahkan telah menerbitkan Peraturan Pemerintah No. 47 tahun 2012 tentang Tanggung Jawab Sosial dan Lingkungan (seterusnya disingkat TJSL). Perseroan Terbatas merupakan perusahaan yang memperoleh amanat langsung dari Undang-Undang No. 40 tahun 2007 tentang Perseroan Terbatas karena melihat pentingnya hal ini (Kamal, 2013; Rahmatullah, 2013). Peraturan Pemerintah ini mengatur Perseroan Terbatas agar melaksanakan TJSL (CSR) sebagai pelaksanaan tanggung jawab mereka terhadap lingkungan dan sosial terutama bagi perusahaan yang berkaitan dengan sumber daya alam. Peraturan Pemerintah ini menunjukkan keseriusan pemerintah terhadap pentingnya menjaga keselarasan antara perusahaan dengan masyarakat dan lingkungannya dengan tujuan keberlanjutan (sustainability).

Gubernur Bali bahkan telah mengukuhkan Forum Tanggung Jawab Sosial (CSR) dalam dunia usaha dalam penyelenggaraan kesejahteraan sosial Provinsi Bali masa bakti 2012-2016 (Pemerintah Provinsi Bali, 2012). Forum ini bertujuan untuk mengajak perusahaan yang beroperasi di Bali untuk berkomitmen mengentaskan kemiskinan dan menjaga kelestarian lingkungan tanpa memandang jenis usahanya. Isu CSR telah pula menjadi perhatian dan dilaksanakan oleh perusahaan yang ada di seluruh dunia, akan tetapi implementasinya berbeda tergantung pada negara, industri dan perusahaan (Yu et al., 2012).

Implementasi CSR di industri pariwisata dan hospitaliti telah menunjukkan peningkatan yang signifikan pada negara yang sudah berkembang. Walaupun demikian masih belum ada standar yang merupakan panduan dalam melaksanakan kegiatan CSR dalam industri pariwisata khususnya pada negara yang berkembang. Peneliti Holcomb, Okumus, dan Bilgihan melakukan observasi bahwa ditemukan masih terbatasnya penelitian tentang aktifitas CSR dalam perusahaan hospitaliti dan pariwisata.

Penelitian yang dilakukan oleh Dewi, N.I.K. (2013) yang meneliti tentang Eksplorasi Pelaksanaan Program Corporate Social Responsibility Studi Kasus Pada Hotel Butik di Bali. Penelitian ini menemukan bahwa terdapat komitmen yang kuat terhadap pelaksanaan program CSR baik itu internal maupun eksternal yang sesuai dengan konsep Triple Bottom Line. Adapun jenis program CSR yang telah dilakukan sesuai dengan cause promotions, corporate societal marketing, corporate philanthropy, community voluntering, dan socially responsible business practice. Manfaat yang diperoleh dengan melaksanakan program CSR adalah reputasi (dengan menerima beberapa penghargaan) dan meningkatkan kemampuan bersaing perusahaan (competitive advantage).

Penelitian lainnya dilakukan oleh Budiasni. N.W.N., dkk (2015) dengan judul Implementasi Corporate Social Responsibility Berdasarkan Konsep Tri Hita Karana (Studi Kasus Hotel Como Shambala Estate di Banjar Begawan Kecamatan Payangan Kabupaten Gianyar). Penelitian tersebut memperoleh temuan bahwa $a$ ) Hotel Como Shambala Estate merupakan salah satu hotel yang mengimplementasikan CSR sebagai wujud tanggung jawab sosial. Meski dalam proses implementasi $C S R$ tersebut terdapat kendala. Kesibukan dan kurang sadarnya masyarakat terhadap kebersihan lingkungan menjadi kendala optimalisasi program kebersihan lingkungan. Berdasarkan pengumpulan data dan hasil penelitian secara kualitatif di Hotel Como Shambala Estate di atas telah menunaikan tanggung jawab sosialnya dengan mengimplementasikan program sosial Como approach (pendekatan Como) berdasarkan konsep Tri Hita Karana. Dikatakan berdasarkan konsep Tri Hita Karana karena dalam proses pengimplementasian program sosial tersebut, mengintegrasikan tiga unsur yang seirama dengan konsep Tri Hita Karana. Tanggung 
jawab sosial tersebut bertujuan menjalin hubungan yang harmonis dengan masyarakat (pawongan), lingkungan (palemahan), dan dilengkapi dengan jalinan dengan aspek Ketuhanan (parahyangan). b) Pengalokasian biaya untuk pembiayaan Como approach dialokasikan dalam dua akun biaya yaitu biaya administrasi dan umum $(A \& G)$, dan $H R D$. Biaya yang sifatnya tetap atau rutin akan dialokasikan dalam biaya $A \& G$, sedangkan biaya yang sifatnya insidentil akan dialokasikan dalam biaya HRD. c. Pegalokasian biaya untuk keperluan kepedulian sosial como approach tersebut tidak membebani pihak Hotel Como Shambala Estate.

Pihak Hotel Como Shambala Estate memiliki komitmen untuk membantu masyarakat secara penuh dengan tujuan diperolehnya keberterimaan masyarakat atas keberadaan hotel. Keberterimaan masyarakat sekitar sangat penting bagi kelangsungan perusahaan, jika keberterimaan tersebut tidak diperoleh berarti dukungan masyarakat atau komitmen untuk saling membantu antara masyarakat dengan hotel tidak dapat diaplikasikan. Tidak adanya dukungan masyarakat sekitar akan melemahkan berkembangnya hotel atau kelangsungan hotel kedepannya.

Hotel didorong untuk bersahabat dengan lingkungan (green hotel) dalam operasinya seperti memperhatikan praktek-praktek yang bersahabat dengan lingkungan untuk mencegah kerusakan lingkungan dan polusi (Tzschentke, Kirk, \& Lynch, 2008). CSR di industri perhotelan di Bali sejalan dengan implementasi CSR di seluruh dunia, walaupun tidak sepesat bila dibandingkan dengan implementasi di perusahaan yang berkaitan dengan sumber daya alam seperti perusahaan pertambangan (Yogimitha, 2011). Hal ini dikarenakan CSR di industri perhotelan bukan merupakan kewajiban hanya kesukarelaan. Walaupun demikian, CSR sangatlah penting dilaksanakan karena adanya manfaat yang diperoleh seperti yang telah dinyatakan oleh Kotler dan Lee (2005) serta Yu et al. (2012) terutama dalam hal meningkatkan citra perusahaan dan keberlanjutan perusahaan.

Penelitian ini bertujuan untuk mengeksplorasi bagaimana aplikasi CSR pada industri pariwisata khususnya Biro Perjalanan Wisata yang ada di Ubud Gianyar., apakah sejalan dengan konsep environmentally friendly travel. Seperti diketahui bersama bahwa daerah Ubud sebagai dalah satu destinasi pariwista yang berkembang meninggalkan destinasi pariwisata lainnya di Bali. Melalui searching goggle: www.google.com/maps/search/tour+operator diketahui ada 17 Biro Perjalanan Wisata yang ada di Daerah Ubud, Gianyar. Pendekatan yang dilakukan dalam penelitian ini adalah sejauh mana aktifitas CSR yang diterapkan (apa yang dilakukan dan mengapa melakukan itu?). Aspek kunci dari CSR bidang pariwisata adalah bagaimana mengadopsi praktek pertanggung jawaban berjalan seiring degan bisnis yang dijalankan agar tetap dapat berkelanjutan/ sustainable (Teller \& Sharpley, 2008). Menurut Barton (2010) ada tiga level untuk mengidentifikasi aplikasi CSR yakni reaktif, proaktif dan aktif. Pada level reaktif ketika perusahaan berpartisipasi dengan memberi respon melalui memberi dukungan atas kegiatan pemangku kepentingan di masyarakat. Level yang lebih tinggi yakni proaktif yakni perusahaan menangkap peluang untuk dapat melibatkan diri pada proyek lokal. Level tertinggi yakni aktif dimana perusahaan terlibat untuk mendukung masyarakat, mencapai tujuan bersama dengan menjalin kerjasama dengan kelompok atau proyek yang ada.

Penerapan CSR dapat dilakukan dengan membangun tahapan, seperti halnya pemahaman atas mature (kematangan) dalam penerapan CSR dimana berdasar pemahaman dan praktek CSR dilaksanakan sesuai dengan 5 tahap dalam organizational learning yakni tahap defensive, compliance, managerial, dan strategic.

\section{TINJAUAN PUSTAKA}

Adopsi CSR penerapannya akan berbeda sesuai dengan bisnis inti perusahaan. Untuk Industri pariwisata mengadopsi praktik pertanggung jawaban yang dijalankan di perusahaan untuk mendukung agar bisnis dapat berkelanjutan (Telfer \& Sharpley, 2008). 
Menurut Barton (2010) ada tiga level untuk mengidentifikasi aplikasi CSR yakni reaktif, proaktif dan aktif. Pada level reaktif ketika perusahaan berpartisipasi dengan memberi respon dengan memberi dukungan atas kegiatan pemangku kepentingan di masyarakat. Level yang lebih tinggi yakni proaktif yakni perusahaan menangkap peluang untuk dapat melibatkan diri pada proyek lokal. Level tertinggi yakni aktif dimana perusahaan terlibat untuk mendukung masyarakat, dengan mencapai tujuan bersama melalui kerjasama dengan kelompok atau proyek yang ada.

Tahapan dalam mengimplementasikan kegiatan CSR, sebagai perusahaan yang matang dalam memahami dan melaksanakan CSR, mereka akan melalui lima tahapan dari pembelajaran organisasi (organization learning) dalam menerapkan pertanggung jawaban perusahaan. Zadek (2004) memberi model yang di dalamnya termasuk lima tahapan yakni Defensive stage, compliance stage, managerial stage, strategic stage dan civil stage. Pada masing-masing tahapan mencerminkan apa yang dilakukan oleh perusahaan dan mengapa melakukan hal tersebut. Kegiatan organisasi dan alasan dibalik kegiatan tersebut yang dilakukan terhadap berbagai pemangku kepentingan yakni kepada siapa seharusnya organisasi memiliki pertanggung jawaban seperti konsumen, sumber daya manusia, masyarakat pada tahap mana yang telah dilakukan. Dalam model tersebut aplikasinya tergantung apakah dalam tahap membangun (defensive, compliance) atau sudah terbangun (managerial, strategic dan civil).

\section{METODE PENELITIAN}

Penelitian ini menggunakan pendekatan penelitian kualitatif karena mengungkapkan dan membahas masalah dengan memaparkan, menafsirkan, dan menggambarkan keadaan serta peristiwa yang terjadi pada saat penelitian berlangsung kemudiaan dianalisis sebagai suatu hasil penelitian tetapi tidak digunakan untuk membuat kesimpulan secara luas. Tujuannya untuk membuat deskripsi, gambaran, atau lukisan secara sistematis, faktual, dan akurat mengenai fakta-fakta, sifat-sifat serta hubungan fenomena yang diselidiki.

Data dikumpulkan dengan melakukan Wawancara mendalam (in defth interview), yaitu penulis mengadakan wawancara dengan pihak perusahaan yang diwakili oleh perwakilan perusahaan yang berwenang guna memperoleh informasi yang dibutuhkan sehingga penulis mendapatkan gambaran mengenai aplikasi CSR dan tahapan CSR yang dilakukan oleh perusahaan.

\section{HASIL DAN PEMBAHASAN}

\subsection{Deskripsi Data}

Jumlah Biro Perjalanan Wisata yang berhasil diperoleh datanya berdasar wawancara secara mendalam adalah berjumlah delapan (8) Biro Perjalanan Wisata dari tujuh belas (17) Biro Perjalanan Wisata yang ada. Setelah ditelusuri di lapangan bahwa yang terlihat di google map sebagai Biro Perjalanan Wisata banyak yang masih terbatas dalam bentuk pusat informasi pariwisata.

\subsection{PEMBAHASAN}

Berdasarkan beberapa pertanyaan yang disampaikan kepada pengurus Biro Perjalanan Wisata tentang bagaimana aplikasi CSR berdasarkan kategori menurut Barton (2010) dimana ada tiga level untuk mengidentifikasi aplikasi CSR yang telah dilaksanakan yakni reaktif, proaktif dan aktif. Pada level reaktif ketika perusahaan berpartisipasi dengan memberi respon dengan memberi dukungan atas kegiatan pemangku kepentingan di masyarakat. Level yang lebih tinggi yakni proaktif yakni perusahaan menangkap peluang untuk dapat melibatkan diri pada proyek lokal. Level tertinggi yakni aktif dimana perusahaan terlibat untuk mendukung masyarakat, dengan mencapai tujuan bersama 
melalui kerjasama dengan kelompok atau proyek yang ada. Sebagian besar Biro Perjalanan Wisata di Ubud masih dalam tataran reaktif yakni memberi respon dengan memberi dukungan atas kegiatan pemangku kepentingan seperti melakukan kegiatan ketika ada informasi untuk kerja bakti yakni melakukan gotong royong pembersihan di lingkungan dengan krama banjar dan perusahaan-perusahaan sekitar, memberi sumbangan pembuatan ogoh-ogoh dan dana punia pada upacara adat masyarakat sekitar, selain itu pula memberi dukungan dalam membangun Gedung Banjar Adat.

CSR yang dilakukan oleh Biro Perjalanan wisata tergantung pada tingkat kemampuan financial yang dimiliki, sebagian perusahaan yang lebih besar sudah proaktif dengan melakukan selain taat membayar pajak juga membayar iuran subak, iuran banjar, memberi dana punia ke pura-pura, menyediakan tong sampah, menyumbang alat-alat tulis ke sekolah membayar biaya bersih-bersih di pura dan sebagainya. Diantaranya terdapat pula Biro Perjalanan Wisata yang sudah pada tatanan aktif dengan bekerja sama dengan dokter-dokter ahli dan rumah sakit yakni dengan membentuk klinik yang bernama Klinik Bali Sari berupa yayasan yakni melakukan kegiatan social setiap bulannya yang bergerak untuk membantu kesehatan masyarakat terpencil, memberi pengobatan gratis dan sembako gratis bagi masyarakat terpencil.

Selain aspek eksternal yang dilakukan sejumlah Biro Perjalanan Wisata, dari aspek internal perusahaan telah memperhatikan sumber daya manusia di dalamnya dengan mengikut sertakan dalam asuransi kesehatan (BPJS) dan melakukan rekrutmen dengan memberdayakan masyarakat sekitar.

Ada lima tahapan dalam melaksanakan CSR yakni tahap defensive, compliance, managerial, strategic dan civil. Pada masing-masing tahapan mencerminkan apa yang dilakukan oleh perusahaan dan mengapa melakukan hal tersebut. Kegiatan organisasi dan alasan dibalik kegiatan tersebut yang dilakukan terhadap berbagai pemangku kepentingan yakni kepada siapa seharusnya organisasi memiliki pertanggung jawaban seperti konsumen, sumber daya manusia, masyarakat pada tahap mana yang telah dilakukan. Dalam model tersebut aplikasinya tergantung apakah dalam tahap membangun (defensive, compliance) atau sudah terbangun (managerial, strategic dan civil).

Berdasarkan data yang diperoleh di lapangan sebagian besar baru melakukan pada tahap defensive dan compliance yakni tahap membangun yakni membangun image di masyarakat dengan taat membayar pajak, ketika diperlukan memberi sumbangan atau dana punia, dan iuran-iuran lainnya agar keberadaan perusahaan diterima di masyarakat.

Tahap berikutnya yakni tahap managerial dimana kegiatan CSR sudah terintegrasi dengan kegiatan inti perusahaan dengan menyiapkan budget yang disisihkan dari pendapatan yang diperoleh oleh perusahaan untuk menunjang kegiatan yang bersifat rutin untuk membantu kegiatan- kegiatan masyarakat sekitar. Tahap pelaksanaan CSR paling tinggi ada pada tahap strategic karena sudah adanya beberapa Biro Perjalanan Wisata yang telah berusaha untuk melakukan kerjasama dengan stakeholder yakni kerjasama dengan dokter-dokter ahli dan rumah sakit untuk peduli terhadap kesehatan masyarakat di daerah terpencil dimana secara rutin memberikan pengobatan gratis dan pemberian sembako.

\section{KESIMPULAN}

Aplikasi CSR yang telah dilakukan oleh Biro Perjalanan Wisata di Ubud sebagian besar masih bersifat reaktif, walaupun ada diantaranya sudah melakukan secara proaktif dan aktif. Dikaitkan dengan organizational learning diperoleh kesimpulan bahwa tahapan CSR yang telah dilakukan oleh Biro Perjalanan Wisata di Ubud sebagian besar masih pada level defensive dan compliance. Hanya beberapa yang sudah pada level managerial dan strategic. 
Saran yang bisa diberikan hendaknya semua Biro Perjalanan Wisata di Ubud diharapkan lebih peduli terhadap pelaksanaan tri bottom line bidang pariwisata yang menyangkut aspek ekonomi, sosial dan lingkungan, mengingat dampak positif pelaksanaan tersebut terhadap masyarakat. Perlu dilakukan sosialisasi oleh pihak terkait untuk menyadarkan semua pelaku bisnis bidang pariwisata untuk peduli terhadap lingkungan, kesejahteraan masyarakat di internal perusahaan dan masyarakat pada umumnya.

Penelitian ini memiliki ruang lingkup hanya di Ubud, belum bisa memberikan gambaran untuk keseluruhan biro perjalanan wisata diseluruh Bali. Penelitian selanjutnya bisa dikembangkan dalam cakupan yang lebih luas. Mungkin tidak hanya di Biro Perjalanan Wisata tapi di Biro Perjalanan Umum atau industri Pariwisata secara menyeluruh.

\section{PERNYATAAN PENGHARGAAN}

Melalui kesempatan ini penulis menyampaikan terima kasih dan penghargaan pada penyandang dana riset yakni Anggaran DIPA Politeknik Pariwisata Bali Tahun 2019 dan seluruh manajemen Biro Perjalanan Wisata yang telah berperan penting dalam penulisan artikel ini.

\section{DAFTAR PUSTAKA}

Archer, B., Cooper, C., \& Ruhanen, L. (1998). The positive and negative impacts of tourism. In W. F. Theobald (Ed.),Global), Global tourism (pp. 79-102). Oxford, UK: Butterworth-Heinemann.

Barton, C. E. (2010). Understanding corporate social responsibility engagement in small and medium tourism businesses (Unpublished bachelor's dissertation). University of Technology, Sydney, Australia.Buckley, R., \& Pannell, J. (1990). Environmental impacts of tourism and recreation in national parks and conservation reserves. Journal of Tourism Studies, 1(1), 24-32.

Collier, J., \& Estebban, R. (2007). Corporate social responsibility and employee commitment. Business Ethics: A European Review, 16(1).

Crowter, D. \& Aras, G. (2008). Corporate Social Responsibility. Diunduh pada tanggal 31Pebruari 2015 dari http://bookboon.com.

Dewi, N.I.K. (2013). Exploring and understanding relationship marketing and networks in the hotel industry: the case of hotels in the Bali Province of the Republic of Indonesia (Unpublished doctoral dissertation). University of Salford, Manchester

Kamal, M. (2013). CSR Tidak Lagi Wajib. Diunduh pada tanggal 31 Pebruari 2015 dari http://www.hukumonline.com/berita/baca/lt502d8a41c9e04/CSR Tr -tidak-lagiwajibbroleh--miko-amal-phd

Kang, K. H., Lee, S., \& Huh, C. (2010). Impacts of positive and negative corporate social responsibility activities on company performance in the hospitality

Kotler, P \& Lee, N. (2005). Corporate social responsibility: Doing the most good for your company and your cause. New Jersey: John Wiley \& Sons.

Lepp, A. (2007). Residents' attitudes towards tourism in Bigodi Village, Uganda. Tourism Management, 28(3), 876-885.

Mathieson, A., \& Wall, G. (1982). Tourism, economic, physical and social impacts. New York, NY: Longman.

Mattera, M., \& Melgarejo, A. M. (2012). Strategic implications of corporate social responsibility in hotel industry: A comparative research between NH Hotels and Melia Hotels International. Higher Learning Research Communications, 2(4), 37-53. 
Nyahunzvi, K. D. (2013). CSR reportingCSR reporting among Zimbabwe's hotel groups: A content analysis. International Journal of Contemporary Hospitality Management, 25(4), 595-613

Pemerintah Provinsi Bali. (2012). Gubernur Kukuhkan Forum Tanggung Jawab Sosial Dunia Usaha (CSR )CSR). Diunduh pada tanggal 25 Pebruari 2015 dari http://www.baliprov.go.id/ Gubernur-Kukuhkan-Forum-Tanggung Jawab-SosialDunia-Usaha--CSR -2

Rahmatullah. (2010). Masalah Pengelolaan Program Corporate Social Responsibility (CSR) Pada Sektor Pertambangan. Diunduh pada tanggal 25 Pebruari 2015 dari http://www.rahmatullah.net/2010/05/masalah-pengelolaan-programcorporate.html

Sugiyono (2007). Metode Penelitian kualitatif dan kuantitatif. Bandung: Alfabeta

Telfer, D., \& Sharpley, R. (2008) Tourism and developmentin the developing world. London, UK: Routledge

Turcsanyi, J., \& Sisaye, S. (2013). Corporate social responsibility and its link to financial performance: Application to Johnson \& Johnson, a pharmaceutical company. World Journal of Science, Technology and Sustainable Development, 10(1). pp. 4-18.

Tzschentke, N. A., Kirk, D., \& Lynch, P.A. (2008). Going green: Decisional factors in small hospitality operations. International Journal of Hospitality Management, 27, pp. 126133.

Waldman, D., Kenett, R. S., \& Zilberg, T. (2010). Corporate Social Responsibility: What it really is, Why it's so important, and How it should be managed. School of Global Management. Diunduh pada tanggal 8 Agustus 2015 dari http://jims-israel.org

Welford, R. (2005). Corporate Social Responsibility in Europe, North America and Asia: 2004 survey results. Journal of Corporate Citizenship 17, 33-52.

Yogimitha. (2011). Penerapan CSR Terhadap Hotel Berbentuk PT di Bali. Diunduh pada tanggal 25 Pebruari 2015 dari http://yogimitha.blogspot.com/2011/11/penerapanCSR terhadap-hotel-berbentuk.html

Zadek, S. (2004). The Path to Corporate Responsibility. Harvard Business Review, 82(12), 125-132. 